\title{
Positive Feedback by Autoexcitatory Neuropeptides in Neuroendocrine Bag Cells of Aplysia
}

\author{
Richard O. Brown ${ }^{\mathrm{a}}$ and Earl Mayeri \\ Division of Neuroscience, Department of Physiology, University of California, San Francisco, California 94143
}

\begin{abstract}
Neurohormones are often secreted in large amounts from neuroendocrine cells during episodes of synchronous, repetitive spike activity. We report evidence that this pattern of activity in the neuroendocrine bag cells of Aplysia involves positive feedback by autoexcitatory transmitters. Intracellular stimulation of individual bag cells caused slow depolarizing afterpotentials and synchronous afterdischarges in the entire population of bag cells. Application of the bathing medium collected during bag cell activity mimicked these responses. Application of $\alpha$-, $\beta$-, or $\gamma$-bag cell peptides (BCPs), 3 structurally related neuropeptides released from bag cells, also mimicked these responses. These autoexcitatory BCPs fulfill most of the strict criteria necessary for classification as neurotransmitters in this system. This is the first biological activity reported for $\beta$ - and $\gamma$-BCPs and brings to 4 the number of bag cell neuropeptides derived from the egglaying hormone/BCP precursor that are putative cotransmitters. Positive feedback by autoexcitatory transmission may provide a general mechanism for the generation of episodic activity in neuroendocrine systems.
\end{abstract}

Neuroendocrine systems regulate physiology and behavior by releasing neurohormones that enter the circulation to act on distant tissues. To meet this functional requirement, neuroendocrine cells must secrete large amounts of chemical messengers, and this secretion often occurs in discrete episodes. In a variety of invertebrate and vertebrate systems such pulsatile neurohormone release has been associated with coordinated bursts of action potentials in neuroendocrine cells (Kupfermann and Kandel, 1970; Vlieger et al., 1980; Lincoln et al., 1985; Copenhaver and Truman, 1986). However, the neuronal mechanisms underlying this pattern of activity are not well understood.

The bag cells are neuroendocrine cells in the marine mollusk Aplysia that release multiple neuropeptides to control egg-laying behavior (reviewed by Mayeri and Rothman, 1985). The bag cells are an apparently homogeneous group of neurons that comprise 2 clusters of approximately 400 neurons each at the rostral end of the abdominal ganglion. They are normally electrically silent, but episodically fire synchronous, repetitive burst dis-

\footnotetext{
Received July 20, 1988; revised Sept. 8, 1988; accepted Sept. 16, 1988.

We thank Drs. R. F. Jansen, J. A. Kauer, and S. M. Pulst for their valuable comments on the manuscript, and Steinhart Aquarium, San Francisco, for generously allowing us to use their aquarium facilities. This research was supported by NIH Grant NS16490.

Correspondence should be addressed to Earl Mayeri at the above address.

a Present address: Exploratorium, 3601 Lyon Street, San Francisco, CA 94123.

Copyright (C) 1989 Society for Neuroscience $0270-6474 / 89 / 041443-09 \$ 02.00 / 0$
}

charges (also termed afterdischarges) that typically last 15-30 min. In intact animals, each bag cell burst discharge is associated with egg release from the ovotestis and the accompanying stereotyped egg-laying behavior. During burst discharges, the bag cells release large amounts of neuropeptides derived from a common precursor, including egg-laying hormone (ELH), and $\alpha$-, $\beta$-, and $\gamma$-bag cell peptides (BCPs). ELH functions both as a neurohormone to cause egg release from the ovotestis (Rothman et al., 1983) and as an excitatory transmitter onto various target neurons (Mayeri et al., 1985). $\alpha$-BCP is an inhibitory transmitter onto various other target neurons (Rothman et al., 1983; Sigvardt et al., 1986). $\beta$ - and $\gamma$-BCPs are structurally related to $\alpha$-BCP but do not share its inhibitory activity (Sigvardt et al., 1986).

In the isolated nervous system, the bag cells can be activated by a variety of electrical or chemical stimuli (Kupfermann and Kandel, 1970; Dudek and Blankenship, 1977; Haskins and Blankenship, 1979; Heller et al., 1980; Strumwasser et al., 1982; Rothman et al., 1983). The characteristics of the resulting burst discharges seem independent of the type and intensity of the stimulus and are essentially the same as those of the spontaneous burst discharges recorded from bag cells in vivo (Pinsker and Dudek, 1977). This suggests that the stereotyped burst discharge is an intrinsic property of the bag cells.

Many of the bag cell processes wrap around the pleuroabdominal connectives to form dense neuritic cuffs just rostral to each bag cell cluster (Frazier et al., 1967). This neuritic cuff is the site at which bag cell activity is normally initiated (Haskins and Blankenship, 1979) and is capable of supporting normal burst discharges even when dissected away from the bag cell somata (Kaczmarek et al., 1978). Electrotonic connections between the bag cell processes in this cuff are thought to synchronizc the firing of the bag cells (Kupfermann and Kandel, 1970; Dudek and Blankenship, 1977). Bag cell processes in the cuff label very heavily for immunoreactive ELH and $\alpha$-BCP (Chiu and Strumwasser, 1981; Painter et al., 1986; Pulst et al., 1986), suggesting that very high local concentrations of BCPs may be reached here after release during burst discharges. Thus, the critical interactions underlying the generation of bag cell burst discharges are likely to occur in this neuritic cufr.

The intrinsic all-or-none pattern of bag cell activity and the explosive acceleration of firing rate in the initial stage of burst discharges suggest the involvement of positive feedback. $\alpha$-BCP was previously shown to have excitatory effects on the bag cells (Rothman et al., 1983). We now report evidence that $\alpha-, \beta$-, and $\gamma$-BCPs all function as autoexcitatory transmitters to provide positive feedback in this system. It is suggested that the BCPs released during the initial spikes of bag cell activity act on bag 




Figure 1. Positive fecdback in bag cells. Bag cell discharge produced by intracellular electrical stimulation of an individual bag cell. Simultaneous intracellular recordings were made from 2 right and 1 left bag cells using standard electrophysiological techniques as previously described (Mayeri et al., 1985). The right bag cell in the top trace was stimulated with a $4 \mathrm{sec}$ train of depolarizing pulses (bar; $10^{7} \mathrm{~A}, 50 \mathrm{msec}$ pulses, $5 \mathrm{~Hz}$ ) to cause spiking. This caused a depolarization and discharge of the right bag cell cluster and, subsequently, of the left bag cell cluster. The figure shows the first $40 \mathrm{sec}$ of the discharge, which lasted $18 \mathrm{~min}$.

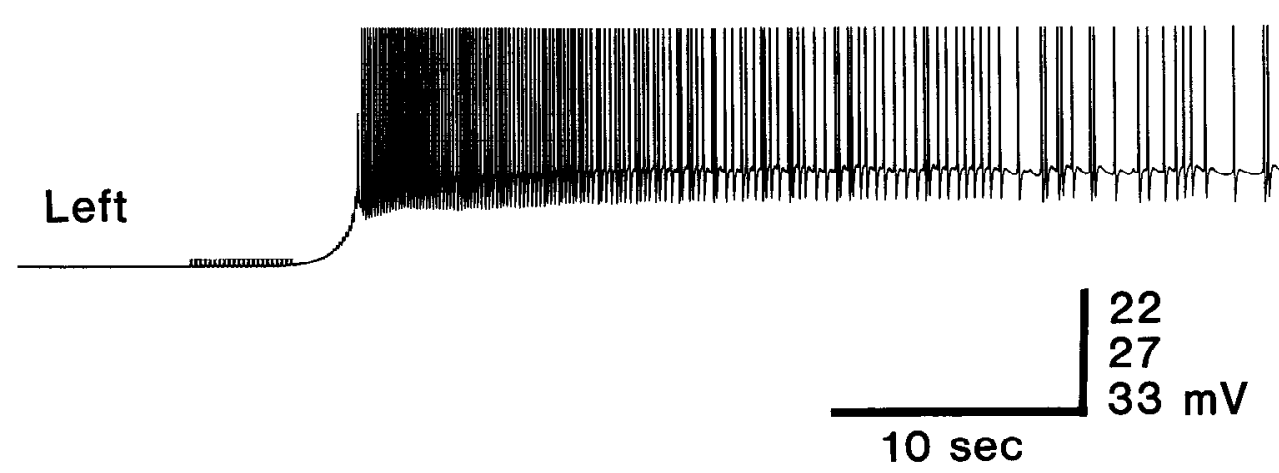

cell autoreceptors to produce depolarizing potentials and further spike activity, contributing to the explosive, all-or-none bag cell burst discharge.

Some of this work was previously presented in abstract form (Brown and Mayeri, 1986).

\section{Materials and Methods}

Electrophysiology. Abdominal ganglia were dissected from large (400$1200 \mathrm{gm}$ ) sexually mature specimens of Aplysia californica, and pinned out in a $1 \mathrm{ml}$ capacity chamber lined with Sylgard resin (Dow-Corning). The preparation was continuously superfused $(30 \mathrm{ml} / \mathrm{hr})$ with seawater containing $10 \mathrm{~mm}$ HEPES buffer (pH 7.6) and $250 \mathrm{mg} /$ liter dextrose. All experiments were performed at room temperature $\left(19-23^{\circ} \mathrm{C}\right)$. Animals were anesthetized by injection $30 \mathrm{~min}$ prior to dissection with isotonic $\mathrm{MgCl}_{2}\left(118 \mathrm{gm} \mathrm{MgCl} \cdot 6 \mathrm{H}_{2} \mathrm{O}\right.$ added to 1 liter $\mathrm{H}_{2} \mathrm{O}$; amount injected equal to $1 / 3$ body weight). Ganglia were pinned under $2 / 3$ seawater, $1 / 3$ isotonic $\mathrm{MgCl}_{2}$, and then washed with normal seawater for at least 1 $\mathrm{hr}$ prior to the experiments. The ganglionic sheath was left intact for all experiments except when otherwise specified. Intracellular recordings were made from up to 4 neurons at a time through potassium acetate $(1.5 \mathrm{M})$-filled glass microelectrodes. The details of the electrophysiology and arterial perfusion of peptides have been published previously (Mayeri et al., 1985). Peptides were applied with protease inhibitors by perfusion through the caudal artery at a flow rate of $3 \mu \mathrm{l} / \mathrm{min}$.

In tests for direct action of the peptides, isolated and desheathed bag cell clusters were bathed in high divalent cation artificial seawater containing (in mM): $\mathrm{NaCl}, 317 ; \mathrm{KCl}, 10 ; \mathrm{CaCl}_{2}, 33 ; \mathrm{MgCl}_{2}, 165$; with 250 $\mathrm{mg} /$ liter dextrose and buffered at $\mathrm{pH} 7.6$ with $10 \mathrm{~mm}$ HEPES. These ionic concentrations were identical to those used to eliminate interneuronal input in the abdominal ganglion by Simmons and Koester (1986).

Serial perfusion. The serial perfusion experiments were conducted as described previously (Mayeri et al., 1985; Sigvardt et al., 1986). Briefly, an abdominal ganglion was placed in a small sealed source chamber with extracellular electrodes placed for stimulating and recording bag cell activity. This source abdominal ganglion was continuously superfused and perfused with seawater containing a battery of protease in- hibitors. A second ganglion was placed in the assay chamber for intracellular and extracellular recordings. The assay ganglion was continuously perfused with the outflow from the source ganglion. The methods of the serial perfusion experiments are further shown in Figure 3.

Peptides and protease inhibitors. All the synthetic bag cell peptides used in these experiments were synthesized by Peninsula Laboratories. The protease inhibitors were $250 \mu \mathrm{g} / \mathrm{ml}$ each of bacitracin (Sigma), hen egg-white trypsin inhibitor (Sigma), lima bean trypsin inhibitor (Sigma), ovomucoid (Worthington), and $100 \mu \mathrm{g} / \mathrm{ml}$ each of phenylalanylalanine (Vega), leupeptin (Peninsula), antipain (Peninsula), and angiotensinconverting enzyme inhibitor (Peninsula).

\section{Results}

\section{Positive feedback in the bag cells}

Intracellular recordings were made from bag cells in isolated abdominal ganglia from large, sexually mature specimens of $A$. californica. Figure 1 shows a typical bag cell burst discharge initiated by the injection of a short ( $4 \mathrm{sec}$ ) train of depolarizing current pulses into a single bag cell (top trace). The stimulated spike activity in this cell produced a slow depolarization of the ipsilateral bag cells (top and middle traces), leading to a synchronous ipsilateral burst discharge. This led, after a delay, to depolarization and activation of the contralateral bag cells (bottom trace). The duration of this bilateral discharge was $18 \mathrm{~min}$. Such intracellular stimulation produced full burst discharges in 16 of 35 preparations, though several trains of pulses were often necessary. The bag cells within each cluster fired highly synchronous action potentials (upper 2 traces), and the 2 clusters were usually nearly synchronous during the early part of the burst discharge. This synchronization of action potentials during bursts is very likely mediated by electrotonic connections in the bag cell cuff neurites (Kupfermann and Kandel, 1970; Dudek and Blankenship, 1977). 
The slow depolarizations produced by intracellular stimulation of a bag cell are seen more clearly in Figure 2. Here, intracellular stimulation of a single bag ccll produced slow depolarizing afterpotentials in the ipsilateral bag cells which was subthreshold to elicit a regenerative afterdischarge. These slow depolarizations typically rose to a peak in 20-60 sec and lasted for up to several minutes. The slow depolarizations and prolonged burst discharges caused by brief intracellular stimulation of individual bag cells indicate a positive-feedback mechanism underlies bag cell activation.

\section{Release of bag cell excitatory factors during bag cell burst. discharges}

One possible positive-feedback mechanism is autoexcitatory transmission by bag cell transmitters acting on bag cell autoreceptors (initially proposed by Kupfermann and Kandel, 1970). Previous experiments designed to test this hypothetical mechanism have yielded negative results (Kupfermann and Kandel, 1970; Strumwasser et al., 1982). We used the serial perfusion apparatus shown in Figure $3 A$ to investigate whether factors with excitatory actions on bag cells are released during bag cell burst discharges. An assay ganglion was continuously perfused with the outflow from a small, sealed chamber containing a source ganglion. A bag cell discharge was initiated in the source ganglion by a brief extracellular stimulation, and the substances released from the source ganglion during the discharge entered the flow into the assay ganglion. After a delay due to the transit time of fluid in the plumbing between the ganglia, the bag cells in the assay ganglion began depolarizing and eventually reached threshold for a regenerative discharge (Fig. 3B). Bag cell depolarizations of 3-12 $\mathrm{mV}$ were seen in 5 of 6 such serial perfusion experiments and led to burst discharges in 3 of them. In a previous set of serial perfusion experiments with only extracellular bag cell recordings, afterdischarges also occurred in 3 of 6 experiments (Sigvardt et al., 1986). These results provide evidence that chemical factors released during bag cell burst discharges have autoexcitatory effects on bag cells.

Autoexcitatory effects of $\alpha-, \beta-$, and $\gamma-B C P$ s

We found that the structurally related neuropeptides $\alpha-, \beta$-, and $\gamma$-BCP all have excitatory actions on bag cells. Figure $4 A-1$ shows the slow depolarization of a bag cell produced by arterial perfusion of $\alpha$-BCP(1-9), the predominant released form of $\alpha$-BCP (Sigvardt et al., 1986). All 3 neuroactive forms of $\alpha$-BCP $[(1-7),(1-8)$, and (1-9)] were approximately equipotent on the bag cells. Arterial perfusion of $8 \mu \mathrm{l}$ of $10^{-6} \mathrm{M} \alpha$-BCP produced bag cell depolarizations of $2-16 \mathrm{mV}$ in 28 of 32 preparations (combined data for the 3 forms of $\alpha$-BCP). $\beta$-BCP had similar effects (Fig. 4A-2) and was approximately equipotent with $\alpha$-BCP. $\gamma$-BCP also depolarized bag cells (Fig. 4A-3) but was less potent than $\alpha$ - and $\beta$-BCP, and was used in fewer experiments. The time course of these depolarizations was similar to that of the depolarizing afterpotentials produced by intracellular bag cell stimulation.

There was day-to-day variability in the sensitivity of the bag cells to the BCPs, but the responses in individual experiments were dose dependent (Fig. $4 B$ ). The typical thresholds for depolarizing responses were between $10^{-8}$ and $10^{-7} \mathrm{M}$ for $\alpha$-BCP and $\beta$-BCP, and between $10^{-7}$ and $10^{-6} \mathrm{M}$ for $\gamma$-BCP. Higher concentrations of $\alpha$ - $\mathrm{BCP}$ or $\beta$-BCP can initiate regenerative burst discharges (see also Rothman et al., 1983; Rock et al., 1986).

The responses to the BCPs quickly desensitized at concen-


$1 \mathrm{~min}$

Figure 2. Depolarizing afterpotentials after bag cell stimulation. Depolarizing afterpotentials were produced by intracellular electrical stimulation of individual bag cells. Intracellular recordings were made from 3 left bag cells. The bag cell in the top trace was stimulated as in Figure 1 to cause spiking (arrow), but the stimulation was insufficient to initiate an afterdischarge. Following the stimulation, slow depolarizing afterpotentials developed which reached peaks of $6 \mathrm{mV}$ in the stimulated cell and $2.5 \mathrm{mV}$ in the other bag cells.

trations above $10^{-6} \mathrm{M}$, or at even lower concentrations with repeated applications. This desensitization process, together with the slow time course of the responses and the difficulty in holding bag cell recordings through many arterial perfusions, made it difficult to compare precisely the potencies of the different BCPs. However, when the BCPs were compared, $\alpha$ - and $\beta$-BCPs had similar potencies, while $\gamma$-BCP was approximately $1 / 10$ th as potent.

In contrast to the BCPs, the atrial gland peptides $\mathrm{A}$ and $\mathrm{B}$, which are homologous to $\alpha$-BCP and can trigger bag cell activity when applied to the head ganglia (Heller et al., 1980; Painter et al., 1986), did not have depolarizing actions on bag cells at concentrations of $20-125 \mu \mathrm{M}$ (10 bag cells in 6 preparations). This indicates that they are not active on the same receptors as the BCPs. While the present study and that of Painter et al. (1986) found no effects of the BCPs on the bag cells in the absence of attached head ganglia, Heller et al. (1980) reported that peptides $A$ and $B$ initiated bag cell burst discharges, with mean latencies of $16 \mathrm{~min}$, when applied to bag cells with the pleuroabdominal connective intact. They were uncertain whether these were postsynaptic effects on the bag cells or presynaptic effects on their inputs, and Strumwasser et al. (1980) favored the latter interpretation.

This is the first biological activity demonstrated for $\beta$ - and $\gamma$-BCP. In an earlier study, a fraction of bag cell extract with excitatory effects on neurons $\mathrm{L} 1$ and $\mathrm{R} 1$ contained a pentapeptide with the same amino acid composition as $\beta-\mathrm{BCP}$, and $\beta-\mathrm{BCP}$ was thus considered a candidate transmitter for the bag cell excitation of these cells (Mayeri et al., 1985). However, applications of synthetic $\beta$-BCP have failed to mimic this activity except when they also activated the bag cells. 
A

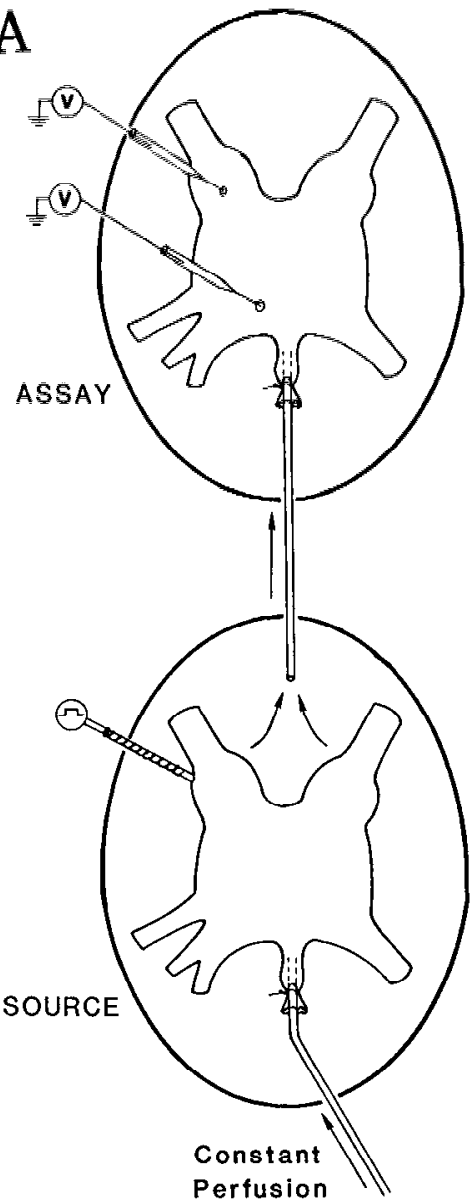

$\mathrm{B}$



LC

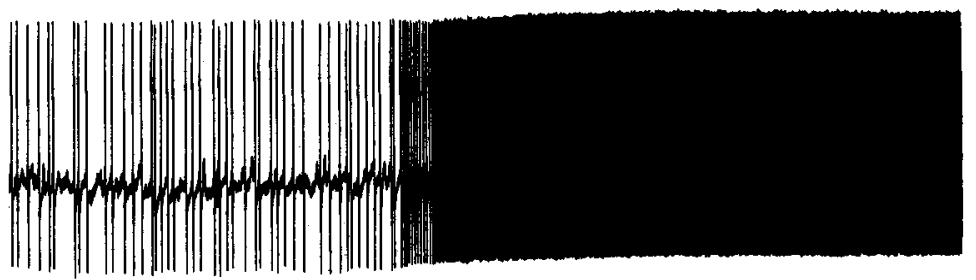

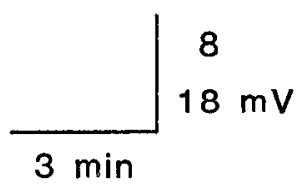

Figure 3. Chemical factors that excite bag cells are released during bag cell activity. $A$, Diagram of the apparatus used in the serial perfusion experiment. The source abdominal ganglion was placed in a small, sealed chamber (bottom of diagram) and continuously arterially perfused and superfused $(7 \mu \mathrm{l} / \mathrm{min}$ each) with buffered seawater containing a mixture of protease inhibitors. Two extracellular electrodes inside the chamber were placed on the bag cell clusters and used for stimulation and recording. The assay abdominal ganglion was placed in an open recording chamber (top of diagram) and arterially perfused with the outflow from the source ganglion (total flow of $14 \mu \mathrm{l} / \mathrm{min}$ into the assay ganglion). $B$, Simultaneous intracellular recordings from a bag cell and an identified target neuron (of the LC cluster) in the assay ganglion. At the arrow, the bag cells in the source ganglion were stimulated, initiating a bag cell discharge that continued beyond the end of the record. The substances released into the flow by this discharge reached the assay ganglion about $3 \mathrm{~min}$ later. The response in the LC cell, an identified target neuron for ELH, is typical of that produced by arterial perfusion of ELH or by normal bag cell activity (Mayeri et al., 1985). Simultaneous with the onset of the LC response, the assay bag cells began depolarizing, leading to an afterdischarge. Bag cell depolarizations were seen in the assay ganglion in 5 out of 6 preparations, with afterdischarges in 3 of these.

\section{Tests for direct action of BCPS on bag cells}

Arterially perfused peptides are distributed throughout the abdominal ganglion, so the cellular sites of their actions are undetermined. To address whether the BCPs act directly on bag cell autoreceptors, we dissected bag cell clusters away from the abdominal ganglion. In this reduced preparation, all the neuronal somata are bag cells. To minimize the possible involvement of severed processes that arose from other cells, the bag cell clusters were bathed in high divalent cation solution. Peptides were pressure-ejected over the isolated cluster and neurites through a wide-mouthed (approximately $100 \mu \mathrm{m}$ ) pipette. Figure $5 A$ shows an excitatory response to $\beta$-BCP seen under these conditions, and Figure $5 B$ shows the dose dependence of the response. Excitatory responses to $\alpha$ - or $\beta$-BCP were seen in 6 of 8 such preparations, suggesting that the peptides act directly on bag cell autoreceptors. In a previous test for direct action, BCPs were applied locally by pressure ejection from broken micropipettes (diameter approximately $10 \mu \mathrm{m}$ ) onto individual bag cell somata. However, no responses were observed in these experiments unless such a large amount of peptide was applied that it diffused beyond the somata (data not shown). We interpret this to indicate that bag cell BCP receptors are not on the somata but may be localized to the neurites. Further evidence of bag cell autoreceptors comes from the finding that BCPs have direct excitatory effects on isolated bag cells in primary cell culture (K. J. Loechner and L. K. Kaczmarek, personal communication; see Discussion).

The responses to applied BCPs desensitized at concentrations above $10^{-6} \mathrm{M}$. If high local concentrations of $\mathrm{BCPs}$ occur during bag cell discharges, these would then be expected to cause desensitization. Figure 6 shows that the excitatory response to $\beta$-BCP was desensitized following bag cell discharges. Arterial perfusion of $10^{-5} \mathrm{M} \beta$-BCP, which normally causes a large consistent depolarization of about $10 \mathrm{mV}$ (Fig. $6 \mathrm{~A}$, upper trace), was ineffective when applied $10 \mathrm{~min}$ after the end of an electrically stimulated bag cell discharge (Fig. $6 \mathrm{~A}$, lower trace). The control and refractory experiments were done in separate prep- 
A

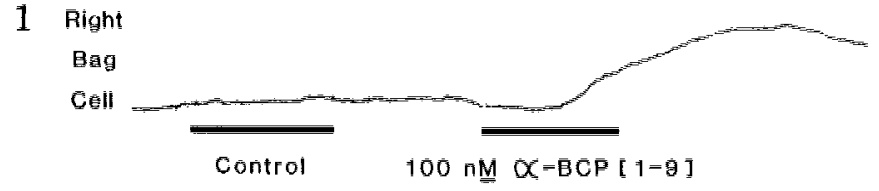

2 Léft

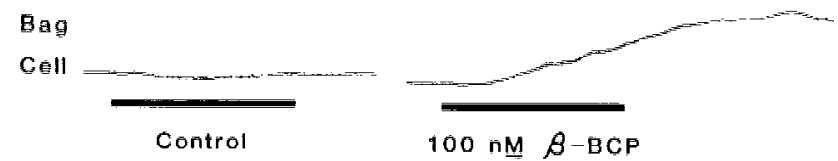

3 Left

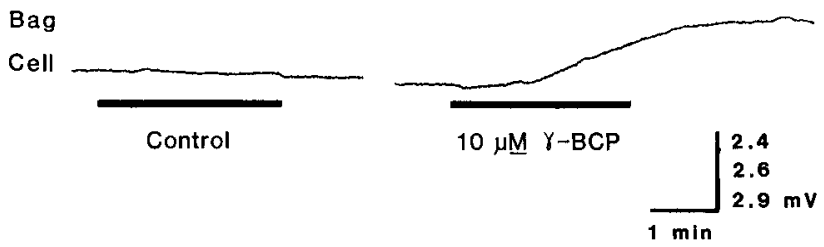

B

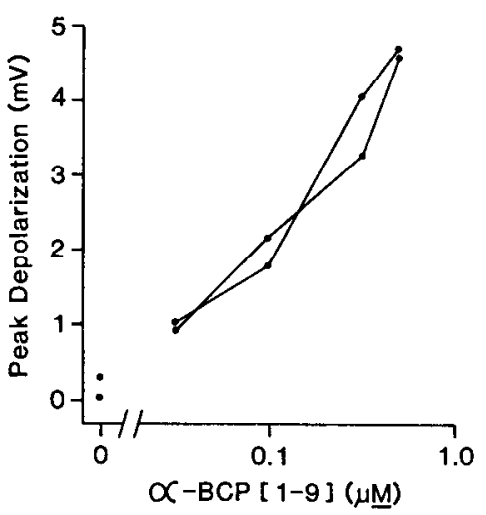

Figure 4. Excitatory actions of BCPs on bag cells. A: 1 , Arterial perfusion of $6 \mu \mathrm{l}$ of $100 \mathrm{nM} \alpha-\mathrm{BCP}(1-9)$ produced a slow depolarization in a bag cell (right). Control application of carrier solution containing the protease inhibitors had no effect (left). 2, Depolarization of bag cell by $8 \mu \mathrm{l}$ of $100 \mathrm{nM} \beta$-BCP. 3. Depolarization of bag cell by $8 \mu \mathrm{l}$ of $10 \mu \mathrm{M}$ $\gamma$-BCP. $B$, Dose dependence of the excitatory response to $\alpha$-BCP. Varying concentrations of $6 \mu \mathrm{l}$ of $\alpha$-BCP(1-9) were arterially perfused, and the peak depolarization was measured. The dose-dependent responses shown were simultaneously recorded from 2 bag cells, including the one shown in $A 1$.

arations to ensure that all of the desensitization seen was due to the bag cell discharge and not to the desensitizing effects of a previous application of $\beta$-BCP. The response to $\alpha$-BCP was also desensitized during the refractory period (not shown). Desensitization to the BCPs during a discharge may provide a necessary mechanism to turn off the positive feedback.

\section{Discussion}

$\alpha-, \beta-$, and $\gamma-B C P$ s as autoexcitatory transmitters

The present findings indicate $\alpha-, \beta-$, and $\gamma$-BCPs have autoexcitatory effects that provide positive feedback in the bag cells. These results, taken with previous data, fulfill most of the strict criteria needed to establish the 3 BCPs as neurotransmitters in this system. The key data are as follows: (1) The BCPs act on bag cell autoreceptors to mimic depolarizations caused by bag cell activity; (2) the BCPs are synthesized by the bag cells and cleaved from a common precursor encoded by a bag cell-specific
A

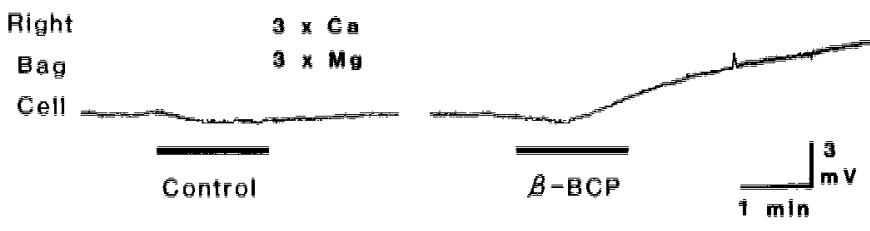

B

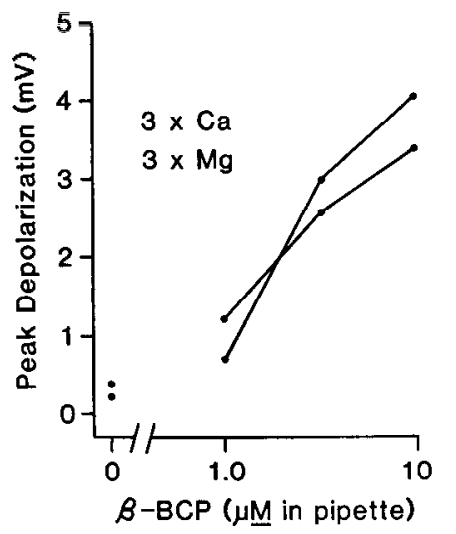

Figure 5. Excitatory response to $\beta-\mathrm{BCP}$ in isolated bag cell clusters in high- $\mathrm{Ca}^{2+}$, high- $\mathrm{Mg}^{2+}$ medium suggests direct action. $A, \mathrm{~A}$ bag cell cluster, with $2 \mathrm{~cm}$ of connective, was dissected away from the abdominal ganglion, partially desheathed, and bathed in high-divalent cation solution for at least $2 \mathrm{hr}$ before the experiment began. Then, $100 \mu \mathrm{l}$ of carrier solution alone or $10 \mu \mathrm{M} \beta$-BCP was pressure-ejected from a pipette over the cluster. $B$, Dose dependence of the excitatory response to $\beta$-BCP in isolated bag cell clusters in high-divalent cation solution. The plot shows the dose-dependent responses of 2 bag cells, from the same preparation as in $A$, to varying concentrations of $\beta$-BCP. Concentrations shown are those in the pipette; the actual concentrations at the target cell were diluted by an unknown factor.

messenger RNA, and they are present in bag cell extracts in approximately equimolar amounts (Rothman et al., 1983; Scheller et al., 1983; Rothman et al., 1985; B. S. Rothman, K. A. Sigvardt, S. M. Pulst, and E. Mayeri, unpublished observations); (3) immunoreactive $\alpha$-BCP is localized to bag cell somata and processes, and in particular, to the neuritic cuff region, which is thought to be the critical site for the generation of bag cell activity (Painter et al., 1986; Pulst et al., 1986); (4) all 3 BCPs are co-released during bag cell discharges (Rothman et al., 1985; Sigvardt et al., 1986), and in quantities that are apparently sufficient to account for the neurally evoked autoexcitatory responses (see below); (5) the BCPs are rapidly inactivated by proteolysis after release (Sigvardt et al., 1986; Rothman et al., 1987; Rothman, Sigvardt, and Mayeri, unpublished observations). This is in contrast to ELH, which functions as a neurohormone and is much more stable (Mayeri et al., 1985).

It is possible to directly compare the neuroactive doses of the BCPs with the quantities released during bag cell activity. The $8 \mu \mathrm{l}$ of $1 \mu \mathrm{M} \alpha-\mathrm{BCP}$ doses that consistently depolarized bag cclls each contained $8 \times 10^{-12} \mathrm{~mol}$ of peptide. By comparison, approximately $10^{-10} \mathrm{~mol}$ of each of the $3 \mathrm{BCPs}$ could be recovered from the material released during a single bag cell discharge in the presence of protease inhibitors (Rothman et al., 1985). To compare these estimates accurately, several additional factors would have to be considered, such as the normal degradation 
A

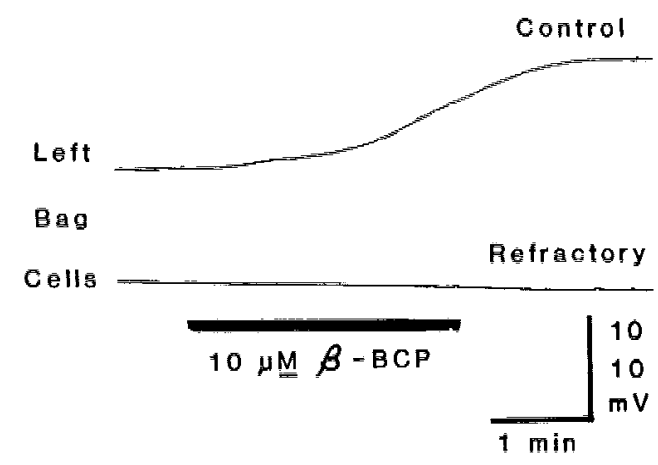

B

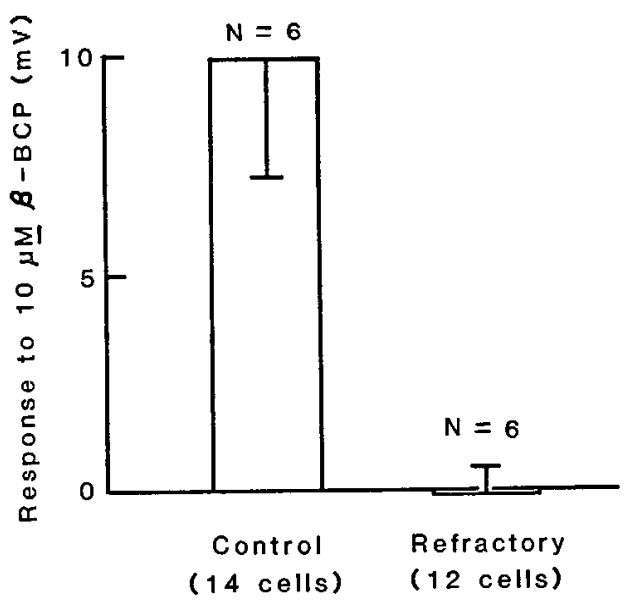

Figure 6. Desensitization of the excitatory response to $\beta$-BCP during the refractory period that follows bag cell discharges. $A$, Intracellular recordings from bag cells in separate preparations. $\beta$-BCP, $10 \mu \mathrm{M}$, was arterially perfused into the abdominal ganglion with no bag cell discharge (Control) or $10 \mathrm{~min}$ after the termination of a bag cell discharge (Refractory). B, Results from application of $10 \mu \mathrm{M} \beta$-BCP to 6 control and 6 refractory preparations. For cach preparation, the response was taken as the mean response of $1-4$ bag cells: control, $9.9 \pm 2.8 \mathrm{mV}$; refractory, $-0.04 \pm 0.63 \mathrm{mV}$. This difference is significant at the $p<$ 0.001 level by Cochran's method for the comparison of independent samples with unequal variances (Snedecor and Cochran, 1967).

of BCPs after release and the losses of BCPs when collecting released material. But as a first estimate, the quantity of BCPs released by bag cells seems more than sufficient to account for the autoexcitatory activity seen in the serial perfusion experiments. Since it is probable that the local BCP concentrations in the critical neuritic cuff during a discharge are much higher than the concentrations reached in the serial perfusion flow, strong autoexcitatory feedback by the BCPs would then be expected to occur during bag cell activity.

These data all indicate autotransmitter roles for the BCPs. An additional critical test, blockade of the neurally evoked response by pharmacological antagonists, cannot be performed until specific antagonists to the BCPs are developed. An alternative approach would be to desensitize the bag cell autoreceptors with high concentrations of BCPs, as was done with the inhibitory $\alpha$-BCP receptors on target neurons (Sigvardt et al., 1986). However, preliminary experiments using this approach have not demonstrated dramatic effects on bag cell activity in the presence of $1 \mathrm{~mm} \alpha$-, $\beta$-, and $\gamma$-BCPs (unpublished observations).
While this may indicate that the autoexcitatory actions of the BCPs are not necessary for the generation of bag cell burst discharges, an alternative interpretation is that there was poor penctration of the undegraded BCPs into the extracellular spaces surrounding the cuff neurites, so that only some of the autoreceptors were actually desensitized. The determination of the precise causal role of autoexcitatory transmission in this system requires further study.

\section{Multiple neuroactive $B C P_{\bar{s}}$ and receptors}

Previous data has shown $\alpha-\overline{\mathrm{B} C \mathrm{P}}$ (Rothman et al $\mathrm{s,}$ 1983; Sigvardt et al., 1986) and ELH (Mayeri et al., 1985) are bag cell neurotransmitters onto target neurons in the abdominal ganglion. The present data indicating that $\alpha-, \beta=$, and $\gamma$-BCPs are autoexcitatory transmitters brings to 4 the number of bag cell neuropeptides derived from the common ELH/BCP precursor that are thought to function as neurotransmitters. The demonstration that these neuropeptides act on the releasing neurons as well as on other central neurons and on peripheral tissues provides a further rationale for the frequent coexistence of multiple putative transmitters in neurons.

$\alpha$-BCP(1-7), $\alpha$-BCP(1-8), $\alpha$-BCP(1-9), and $\beta$-BCP were approximately equipotent in depolarizing bag cells, while $\gamma$-BCP was about $1 / 10$ th as potent. In contrast, for inhibition of the left upper quadrant neurons L2-L6, $\alpha$-BCP $(1-8)$ was 3 timcs as potent as $\alpha-\mathrm{BCP}(1-7)$ and 30 times as potent as $\alpha-\mathrm{BCP}(1-9)$, while $\beta$-BCP and $\gamma$-BCP had little or no activity (Rothman et al., 1983; Sigvardt et al., 1986). These pharmacological distinctions provide evidence for 2 subtypes of $\mathrm{BCP}$ receptor. One subtype mediates the inhibitory response to $\alpha$-BCP and occurs in a large proportion of abdominal ganglion neurons. The other subtype mediates the excitatory response $10 \alpha-, \beta$-, and $\gamma$-BCPs and is seen only in the bag cells, suggesting that it may be specific for bag cell autoreceptors. The atrial gland peptides $\mathrm{A}$ and $\mathrm{B}$, which are homologous to a-BCP and can trigger bag cell discharges when applied to head ganglia (Heller et al., 1980; Painter et al., 1986), but did not appear to have direct excitatory effects on the bag cells, may be acting on yet another related receptor subtype.

Kauer and colleagues (1987) reported that $\alpha$-BCP hyperpolarized bag cells in primary cultures that were up to $2 \mathrm{~d}$ old and lacked extensive neuritic processes. However, hyperpolarizing responses to BCPs were never observed in bag cells in situ, and in subsequent work by this group on bag cells in longer-term cultures, all 3 BCPs were seen to depolarize bag cells (K. J. Loechner and L. K. Kaczmarek, personal communication). If the autoexcitatory receptors are mainly restricted to bag cell neurites, it may be necessary for cultured bag cells to regenerate extensive functional neurites before the autoexcitatory responses return. It is interesting to note that the bag cells in shortterm cultures that lacked autoexcitatory responses also did not generate burst discharges following electrical stimulation. This is consistent with the hypothesis that autoexcitatory transmission is necessary for the generation of bag cell burst discharges, although there are other possible explanations. Kauer et al. (1987) also found that $\alpha$-BCP had only occasional weak depolarizing effects on bag cells in situ, in apparent contrast to our findings, and suggested that the bag cells' autoexcitatory response to $\alpha$-BCP may depend on the use of $\mathrm{MgCl}_{2}$ anesthesia during the dissection (which we routinely used, as described in Materials and Methods, but they did not). However, we have seen autoexcitatory 
A. TEMPORAL SPREAD OF EXCITATION

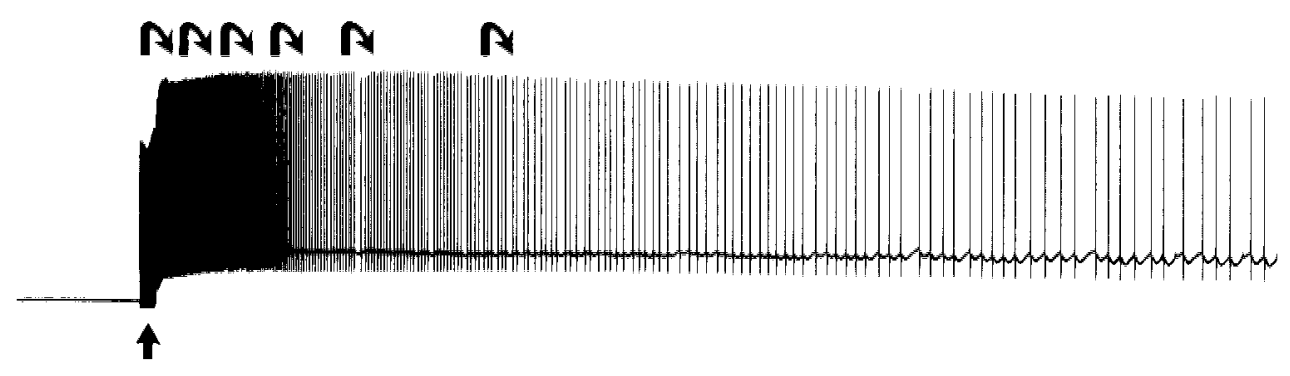

\section{B. SPATIAL SPREAD OF EXCITATION}

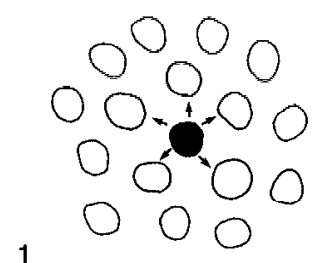

1

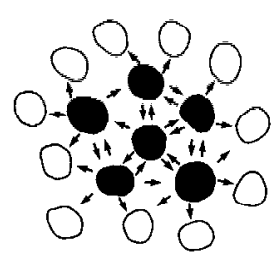

2



Figure 7 . Postulated functions of positive feedback by autoexcilatory transmitters. $A$, Temporal spread of activation in individual neurons. Transient stimulation of an individual cell (arrow at botom) initiates regenerative au= toexcitatory process (repiesented by arrows above), leading to a prolonged afterdischarge. $B$, Spatial spread of activation in a population of neurons. Positive feedback within a functional group of autoexcitatory cells spreads activation from a single cell to the entire cluster. Three successive stages of activity are represented. Filled cells represent active neurons; arrow's represent the spread of excitation to neighboring neurons. responses as well in preparations that were not anesthetized for dissection.

\section{Functions of positive feedback}

Positive feedback by autoexcitatory neuropeptides in the bag cells is postulated to have 2 conceptually distinct consequences. First, the positive feedback in individual cells produces a temporal spread of activity, in which a brief stimulation of a bag cell leads to a prolonged afterdischarge (Fig. $7 A$ ). This is most apparent in the first minute of bag cell burst discharges, when the firing rate of bag cells accelerates rapidly to as much as $10 /$ sec. Second, the positive feedback within a population of cells produces a spatial spread of activity, in which the activation of one or a few cells leads to the coordinated activation of the entire population (Fig. $7 B$ ). This includes the spread of activity among cells in a cluster, between the bilateral clusters, and possibly between different ganglia. In this last regard, we have recently found that intracellular stimulation of pleural ganglion cells containing $\alpha$-BCP-like immunoreactivity causes depolarizations and afterdischarges in the bag cells, and it is hypothesized that the BCPs are the transmitters mediating the descending activation of the bag cells (Brown and Mayeri, 1987; Brown et al., 1989).

Both aspects of the positive feedback contribute to all-ornone, synchronous activity in the bag cells. The resulting prolonged, stereotyped discharge in the bag cells is thought to be important for ensuring that the bag cells, once activated, release a large, fixed quantity of neuropeptides appropriate to generate a complete episode of egg-laying behavior (Kupfermann and Kandel, 1970).

The positive feedback may be turned off by depletion of the autoexcitatory transmitters, desensitization of the autoexcitatory response (Fig. 6), and/or biochemical modifications of bag cell proteins during the discharge (Kaczmarek et al., 1986). This could contribute both to the termination of the discharge and to the subsequent refractory period, during which the bag cells are relatively inexcitable and lack slow depolarizing afterpotentials when stimulated (Kupfermann and Kandel, 1970; Kaczmarek and Kauer, 1983).

The positive feedback by the autoexcitatory BCPs is in addition to other presumed positive-teedback mechanisms, such as electrotonic coupling (Kupfermann and Kandel, 1970; Blankenship and Ilaskins, 1979; Kaczmarek et al., 1979) and voltage- and calcium-dependent currents (Dudek and Blankenship, 1977; De Reimer et al., 1985). Cyclic AMP and polyphosphatidylinositol turnover are also thought to play important roles in the generation of bag cell activity (Kaczmarek et al., 1978, 1986; Strumwasser et al., 1982). The possible relationships among these different mechanisms, and their relative contributions to patterns of bag cell activity, remain to be determined.

While there is growing evidence that autoinhibitory transmission is a common mechanism used to stabilize neuronal activity (Chesselet, 1984), the role of autoexcitatory transmission has not been well established. Pharmacological studies of transmitter release have suggested conjoint regulation by both inhibitory and excitatory autoreceptors on mammalian noradrenergic (Adler-Graschinsky and Langer, 1975) and cholinergic (Wessler et al., 1986) nerves, and at a central cholinergic synapse in Aplysia (Fossicr ct al., 1988). Autocxcitatory transmission was reported in the turtle olfactory bulb, where it may function in signal amplification, but is thought to be under the control of inhibitory feedback (Nicoll and Jahr, 1982). A shift toward net positive feedback in such systems has been suggested as an epileptogenic mechanism (Ayala et al., 1973; Nicoll and Jahr, 1982). In the abdominal ganglion of Aplysia, the electrically coupled L25 neurons, which produce the stereotyped behavior of respiratory pumping, have also been suggested to use autoexcitatory transmitters (Byrne, 1983).

Under normal conditions, the type of intermittent, explosive activity autoexcitatory transmission tends to produce is most often reported in neuroendocrine systems. Besides the bag cells, pulsatile neurohormone secretion has been associated with ep- 
isodic, coordinated electrical activity in the caudodorsal cells (CDC) and the "Light-Yellow Cells" (LYC) in the pond snail Lymnaea stagnalis (Vlieger et al, 1980; Swigchem, 1981), the éclosion hormone cells in the moth Manduca sexta (Copenhaver and Truman, 1986), and some hypothalamic nuclei in mammals (reviewed by Lincoln et al., 1985). Evidence for the involvement of autocxcitatory transmission has been reported for the $L y m$ naea $\mathrm{CDC}$, although the autoexcitatory transmitter has not yet been identified (Maat et al., 1988), and for the hypothalamic oxytocin cells (Freund-Mercier and Richard, 1984; Belin and Moos, 1986; Yamashita et al., 1987). An emerging hypothesis is that autoexcitatory transmission provides a general mechanism for the generation of episodic activity in neuroendocrine systems.

\section{References}

Adler-Graschinsky, E., and S. Z. Langer (1975) Possible role of a $\beta$-adrenoreceptor in the regulation of noradrenaline release by nerve stimulation through a positive feed-back mechanism. Br. J. Pharmacol. 53: 43-50.

Ayala, G. F., M. Dichter, R. J. Gumnit, H. Matsumoto, and W. A. Spencer (1973) Genesis of epileptic interictal spikes. New knowledge of cortical feedback systems suggests a neurophysiological explanation of brief paroxysms. Brain Res. 52: 1-17.

Belin, V., and F. Moos (1986) Paired recordings from supraoptic and paraventricular oxytocin cells in suckled rats: Recruitment and synchronization. J. Physiol. (Lond.) 377: 369-390.

Blankenship, J. E., and J. T. Haskins (1979) Electrotonic coupling among neuroendocrine cells in Aplysia. J. Neurophysiol. 42: 347355.

Brown, R. O., and E. Mayeri (1986) Evidence for exciatory autotransmission mediated by three bag cell neuropeptides in Aplysia. Soc. Neurosci. Abstr. 12: 946.

Brown, R. O., and E. Mayeri (1987) Activation of the bag cells by $\mathrm{ELH} / \mathrm{BCP}$-immunoreactive neurons in the right pleural ganglion of Aplysia californica. Soc. Neurosci. Abstr. 13: 39.

Brown, R. O., S. M. Pulst, and E. Mayeri (1989) The neuroendocrine bag cells of Aplysia are activated by bag cell peptide-containing neurons in the pleural ganglion. J. Neurophysiol. (in press).

Byrne, J. H. (1983) Identification and initial characterization of a cluster of command and pattern-generating neurons underlying respiratory pumping in Aplysia californica. J. Neurophysiol. 49: 491508.

Chesselet, M.-F. (1984) Presynaptic regulation of neurotransmitter release in the brain: Facts and hypothesis. Neuroscience 12:347-375.

Chiu, A. Y., and F. Strumwasser (1981) An immunohistochemical study of the neuropeptidergic bag cells of Aplysia. J. Neurosci. 1:812826.

Copenhaver, P. F., and J. W. Truman (1986) Control of neurosecretion in the moth Manduca sexta: Physiological regulation of the eclosion hormone cells. J. Comp. Physiol. A 158: 445-455.

DeRiemer, S. A., J. A. Strong, K. A. Albert, P. Greengard, and L. K. Kaczmarek (1985) Enhancement of calcium current in Aplysia neurons by phorbol ester and protein kinase C. Nature 313: 313-316.

Dudek, F. E., and J. E. Blankenship (1977) Neuroendocrine bag cells of Aplysia brasiliana. I. Bag cell action potentials and afterdischarge. J. Neurophysiol. 40: 1301-1311.

Fossier, P., B. Poulain, G. Baux, and L. Tauc (1988) Both presynaptic nicotinic-like and muscarinic-like autoreceptors regulate acetylcholine release at an identified neuro-neuronal synapse of Aplysia. Pfluegers Arch. 411: 345-352.

Frazier, W. T., E. R. Kandel, I. Kupfermann, R. Waziri, and R. E. Coggeshall (1967) Morphological and functional properties of identified neurons in the abdominal ganglion of Aplysia californica. J. Neurophysiol. 30: 1288-1351.

Freund-Mercier, M. J., and P. Richard (1984) Electrophysiological evidence for facilitatory control of oxytocin neurons by oxytocin during suckling in the rat. J. Physiol. (Lond.) 352: 447-466.

Haskins, J. T., and J. E. Blankenship (1979) Interactions between bilateral clusters of neuroendocrine cells in Aplysia. J. Neurophysiol. 42: $356-367$.
Heller, E,, L. K. Kaczmarek, M. W. Hunkapiller, L. E. Hood, and F. Strumwasser (1980) Purification and primary structure of two neuroactive peptides that cause bag cell afterdischarge and egg-laying in Aplysia. Proc. Natl Acad. Sci USA 77: 2328-2332.

Kaczmarek, L. K, and J. A. Kauer (1983) Caleiun cntry causes a prolonged reftactory period in peptidergic neurons of $A p / y s i a$. J Neurosci. 3: $2230=2239$.

Kaczmarek, L. K., K. Jennings, and $\bar{F}$. Strumwasser (1978) Ncurótransmitter modulation, phosphodiesterase inhibitor effects, and oAMP

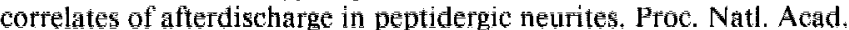
Sci. USA $75: 5200=5204$.

Kaczmarck, L, K., M. Finbow, I. P. Revel, and F. Strumwasser (1979) The morphology and coupling of Aplysia bag cells within the abdom= inal ganglion and in cell culture. J. Neurobiology 10: 535-550.

Kaczmarek, L. K., J. A. Strong, and J. A. Kauer (1986) The role of protein kinases in the control of prolonged changes in neuronal excitability. Prog. Brain Res. 69: 77-90.

Kauer, J. A., T. E. Fisher, and L. K. Kaczmarek (1987) Alpha bag cell peptide directly modulates the excitability of the neurons that release it. J. Neurosci. $7: 3623-3632$.

Kupfermann, I., and E. R. Kandel (1970) Electrophysiological properties and functional interconnections of two symmetrical neurosecretory cluster (bag cells) in abdominal ganglion of Aplysia. J. Neurophysiol. 33: 865-876.

Lincoln, D. W., H. M. Fraser, G. A. Lincoln, G. B. Martin, and A. S. McNeilly (1985) Hypothalamic pulse generators. Kec. Prog. Horm. Res. 41: $369-419$

Maat, A. ter, W. P. M. Geraerts, R. F. Jansen, and N. P. A. Bos (1988) Chemically mediated positive feedback generates long-lasting afterdischarge in a molluscan neuroendocrine system. Brain Res. 438: 7782.

Mayeri, E., and B. S. Rothman (1985) Neuropeptides and the control of egg-laying behavior in Aplysia. In Model Neural Networks and Behavior, A. I. Selverston, ed., pp. 285-301, Plenum, New York.

Mayeri, E., B. S. Rothman, P. H. Brownell, W. D. Branton, and L. Padgett (1985) Nonsynaptic characteristics of neurotransmission mediated by ELH in the abdominal ganglion of Aplysia. J. Neurosci 5: 2060-2077.

Nicoll, R. A., and C. E. Jahr (1982) Self-excitation of olfactory bulb neurones. Nature 296: 441-444.

Painter, S. D., V. Kalman, G. T. Nagle, and J. E. Blankenship (1986) Localization of cells containing immunoreactive alpha-bag cell peptide in the central nervous system of Aplysia californica. In Neurobiology Molluscan Models, H. H. Boer, W. P. M. Geraerts, and J. Joosse, eds., North-Holland Publishing, Amsterdam.

Pinsker, H. M., and F. E. Dudek (1977) Bag cell control of egg-laying in freely-behaving Aplysia. Science 197: 490-493.

Pulst, S.-M., D. Gusman, B. S. Rothman, and E. Mayeri (1986) Coexistence of egg-laying hormone and alpha-bag cell peptide in bag cell neurons of Aplysia indicates that they are a peptidergic multitransmitter system. Neurosci. Letl. 70: 40-45.

Rock, M. K., S. B. Shope, J. E. Blankenship, and D. H. Schlesinger (1986) Effects of synthetic bag cell and atrial gland peptides on identified nerve cells in Aplysia. J. Neurobiol. 17:273-290.

Rothman, B. S., E. Mayeri, R. O. Brown, P.-M. Yuan, and J. E. Shively (1983) Primary structure and neuronal effects of alpha-bag cell peptide, a second candidate neurotransmitter encoded by a single gene in bag cell neurons of Aplysia. Proc. Natl. Acad. Sci. USA 80: 57535757.

Rothman, B. S., K. A. Sigvardt, and E. Mayeri (1985) Co-release of five peptides, ELH, AP, alpha-, beta-, and gamma-BCP, derived from a common precursor protein of the bag cells of Aplysia. Soc. Neurosci. Abstr. 11: 482.

Rothman, B. S., G. A. Phares, and T. A. Groves (1987) Inactivation of alpha-bag cell peptide in the abdominal ganglion of Aplysia. Soc. Neurosci. Abstr. 13: 16

Scheller, R. H., J. F. Jackson, L. B. McAllister, B. S. Rothman, E. Mayeri, and R. Axel (1983) A single gene encodes multiple neuropeptides mediating a stereotyped behavior. Cell 32: 7-22.

Sigvardt, K. A., B. S. Rothman, R. O. Brown, and E. Mayeri (1986) The bag cells of Aplysia as a multitransmitter system: Identification of alpha bag cell peptide as a second neurotransmitter. J. Neurosci. 6: 803-813.

Simmons, L. K., and J. Koester (1986) Serotonin enhances the excitatory acetylcholine response in the RB cell cluster of Aplysia californica. J. Neurosci. 6: 774-781. 
Snedecor, G. W., and W. G. Cochran (1967) Statistical Methods, Gth ed., pp. 114-116, Iowa State University Press, Ames, IA.

Strumwasser, F., L. K. Kaczmarek, A. Y. Chiu, E. Heller, K. R. Jennings, and D. P. Viele (1980) Peptides controlling behavior in Aplysia. In Peptides: Integrators of Cell and Tissue Function, F. E. Bloom, ed., pp. 197-218, Raven, New York.

Strumwasser, F., L. K. Kaczmarek, and K. R. Jennings (1982) Intracellular modulation of membrane channels by cyclic AMP-mediated protein phosphorylation in peptidergic neurons of Aplysia. Fed. Proc. 41: 2933-2939.

Swigchem, H. van (1981) Electrotonic coupling within a cluster of neurosecretory endogenous oscillators in Lymnaea stagnalis (L.). Comp. Biochem. Physiol. 68A: 199-209.
Vlieger, T. A. de, K. S. Kits, A. ter Maat, and J. C. Lodder (1980) Morphology and electrophysiology of the ovulation hormone producing neuroendocrine cells of the freshwater snail Lymnaea stagnalis. J. Exp. Biol. 84: 259-271.

Wessler, I., M. Halank, J. Rasbach, and H. Kilbinger (1986) Presynaptic nicotinic receptors mediating a positive feed-back on transmitter release from the rat phrenic nerve. Naunyn Schmiedeberg's Arch. Pharmacol. 334: 365-372.

Yamashita, H., S. Okuya, K. Inenaga, M. Kasai, S. Uesugi, H. Kannan, and T. Kaneko (1987) Oxytocin predominantly excites putative oxytocin neurons in the rat supraoptic nucleus in vitro. Brain Res. 116: $364-368$ 